\title{
Developing analysis approaches for energy walls
}

\author{
Ida Shafagh ${ }^{1, *}$, and Fleur Loveridge ${ }^{1}$ \\ ${ }^{1}$ School of Civil Engineering, University of Leeds, LS2 9JT, Leeds, UK
}

\begin{abstract}
The use of diaphragm or bored pile walls as ground heat exchangers as well as embedded retaining structures has gained popularity in recent years. Dual use of structure foundations in this way has the potential to reduce the costs of associated ground source heat pump systems, hence providing opportunities for the take up of renewable heating and cooling in our cities. Such systems have been recently constructed as part of major infrastructure schemes in London and Paris. However, there are no standard analytical analysis approaches to permit routine design of the thermal aspects of these novel planar ground heat exchangers. Hence assessment of energy availability on most practical projects either (i) adapts existing methods from ground heat exchangers of different geometry, which runs the risk of incurring errors; or (ii) resorts to time consuming numerical simulation, often in partnership with a research organisation. Neither approach is sustainable for routine roll out of the technology beyond prestige projects. To start to fill this gap in knowledge, this paper presents the first feasibility assessment of developing specific analytical tools for use with energy walls.
\end{abstract}

\section{Introduction}

Foundation heat exchangers, i.e. geothermally activated sub-structures which also function as a ground heat exchanger, are attractive options for providing heating and cooling to residential and commercial buildings which can substantially reduce our dependency on conventional fuels. Currently, there are various types of foundation heat exchangers in use, with energy piles being the most common. Equipping diaphragm walls, which main function is to retain soil around underground space and can also be to support overlying high-rise structures, with heat exchanger pipes is known as diaphragm wall heat exchangers (DWHE). They are also sometime called screen wall heat exchangers and energy walls. Use of DWHEs has emerged recently and thus, compared to other substructure heat exchanger, e.g. energy piles [1-4], less research has been performed to analyse their thermal performance [5].

Early DWHEs were trialled in the Austrian City of Vienna. The first experimental study of heat transfer in three DWHEs was carried out by Brandl [6]. While one of the first numerical study examining the heating and cooling performance of DWHEs was reported by Adam and Markiewicz [7] who used finite element analysis for their research. Xia et al. [8] assessed heat transfer characteristics of DWHEs at a trial site in China. They revealed the factors influencing heat exchange rates in such geostructures by comparing experimental DWHE data to those of borehole heat exchangers (BHE). Sun et al. [9] proposed a design method for DWHEs based on the two-dimensional heat transfer models of DWHEs using the geometry of the Xia et al. [8] study. However, the quality of fit to experimental data was poor in the short term, and the method appears not to have seen routine application. Further numerical investigations were reported by Kürten et al. [10]. They developed a semianalytical calculation model based on thermal resistances which demonstrated good agreement with experimental data, but again the solution is not in common usage.

Bourne-Webb et al. [11] identified commonalities and differences between the methods used for evaluating BHEs and energy geostructures, especially the importance of the excavation space. This aspect was considered in more detail by Bourne-Webb et al. [12], who found that at steady state the main heat transfer mechanism is between the excavation space and the wall rather than between the wall and the ground. Coletto and Sterpi [13] studied the heat transfer effects on the soil temperatures, the wall internal stresses and the soilstructure interaction using coupled thermo-mechanical analysis based on a new case study in Italy. Di Donna et al. [14] highlighted the parameters governing energy efficiency in DWHEs using numerical simulations, again highlighting the importance of the excavation space in the long term, but also showing the relevance of design details in the short term.

Sterpi et al. [15] also investigated the various factors affecting the performance of DWHEs, including the layout of the exchanger pipe, the ratio between exposed and fully embedded parts of the wall, and the thermal boundary at the excavation side, using finite volume analysis. They have suggested an enhanced pipe arrangement that can improve the heat exchange rate by $15.8 \%$ for their studied case. In addition, their study showed that the energy performance can be improved by limiting the thermal interference between pipe branches circulating fluid at different temperatures, and by taking

\footnotetext{
* Corresponding author: I.Shafagh@leeds.ac.uk
} 
advantage of the fully immersed part of the wall, on both faces in direct contact with the soil.

Rammal et al. [16] found that heat exchange rates are improved in the presence of significant groundwater flow and activating the whole length of diaphragm wall. Barla et al. [17] employed finite element thermo-hydro coupled analyses together with the effects of the thermal activation on the surrounding soil to investigate the energy efficiency of DWHEs. Furthermore, they employed finite difference thermo-mechanical analyses to study the mechanical effects induced by the thermal activation. They reported that horizontal pipe layout will maximise the heat exchange rates.

Recently, Shafagh et al. [18] proposed a validated heat transfer model that combines a numerical finite volume representation of a diaphragm wall heat exchanger and surrounding ground and excavation space boundaries based on a Dynamic Thermal Network (DTN) representation. Their model is able to deal with the full geometric complexity of the substructure elements and pipes and non-homogeneous material properties.

A summary of the current understanding on the performance of energy geostructures has been provided by Soga and Rui [5] and by Loveridge et al. [19]. It is suggested that more work is required to build confidence in the use of such substructure heat exchangers.

To date, most research conducted on DWHEs have been concerned with experimental and numerical investigations into their thermal performances. Alternative models of analysis have only been proposed by [9], [10] and [18], and both approaches remain relatively complex. There are currently no available analytical analysis approaches, e.g. like the typical stepresponse approaches used to design BHE, which would permit routine analysis of the thermal aspects of these planar ground heat exchangers in routine practice.

Traditionally the infinite line source (ILS) method is applied to analyse the thermal performance of BHE and derive the step response to thermal input. However, for DWHEs any applicable method needs to take into account the planar shape of the wall and the positioning of the heat exchanger pipes. Therefore their thermal behaviour is better analysed by assuming the planar area normal to heat flux as a heat source. This method is known as "infinite plane source" (IPS). In this research we make the first investigation of the suitability of the IPS to determine its ability to predict the temperature change adjacent to a DWHE.

The following sections detail the methods used, some initial results, and first discussions of the suitability and limitations of the technique. The next steps in developing this approach are also detailed.

\section{Methodology}

\subsection{Approach}

First the equations of the IPS are derived and presented (Section 2.2 below). Subsequently the equations are applied to simulate some case study data of a thermal response test conducted on a DWHE (Section 3). Because the IPS cannot by definition capture all aspects of the thermal wall behaviour, the observed differences are then discussed in Section 3.

\subsection{Derivation of IPS}

By imagining a semi-infinite solid body in the region $x>$ 0 bounded by a plane at $x=0$ with specified heat rate at that surface, $Q_{0}$, the expression that governs the onedimensional transient temperature distribution in the domain is:

$$
\frac{\partial Q}{\partial t}=\alpha \frac{\partial^{2} Q}{\partial x^{2}}
$$

where $t$ is the time and $\alpha$ is the thermal diffusivity. Consideration of the classic heat equation in terms of flux rather than temperature is a useful approach when the main boundary condition is given as a rate. In this case corresponding boundary conditions are:

$$
\begin{array}{ccc}
Q=0 & x>0 & t=0 \\
Q=Q_{0} & x=0 & t>0
\end{array}
$$

The solution to Equation (1) for the given boundary conditions will have the form:

$$
Q=Q_{0} \operatorname{erfc} \frac{x}{\sqrt{4 \alpha t}}
$$

where $\operatorname{erfc}$ is the complimentary error function.

To obtain the temperature distribution in the domain Equation (5) is used:

$$
T(x, t)=-\int_{x}^{\infty} \frac{Q(x, t)}{\lambda} d x
$$

Thus [20]:

$$
T(x, t)=\frac{Q_{0}}{\lambda}\left(\sqrt{\frac{4 \alpha t}{\pi}} e^{-x^{2} / 4 \alpha t-x \operatorname{erf} \frac{x}{\sqrt{4 \alpha t}}}\right)
$$

where $\lambda$ is the thermal conductivity. Equation (6) is known as the plane source heat equation or IPS. It can be applied to calculate temperature distribution at distance $x>0$ from a DWHE at the time $t>0$ as a result of a constant heat flux input to the surface $x=0$ where we assume the wall is located. Thus, values of thermal diffusivity and thermal conductivity used in Equation (6) are those of the ground. To account for the initial temperature of the ground, $T_{0}$, an additional term needs to be added to Equation (6):

$$
\begin{array}{r}
T(x, t)=T_{0}+\frac{Q_{0}}{\lambda}\left(\sqrt{\frac{4 \alpha t}{\pi}} e^{-x^{2} / 4 \alpha t}\right. \\
\left.-x \operatorname{erf} \frac{x}{\sqrt{4 \alpha t}}\right)
\end{array}
$$




\section{Results and discussions}

There is very little case study data available in the literature for validation of models for DWHE thermal behaviour. In this case, variations of measured inlet and outlet fluid temperatures in a prototype DWHE surrounded by ground on both sides is taken from Shafagh et al. [18], Figure 1. This provides a convenient initial cases for testing the IPS model since it is not complicated by the air side boundary on one side of the wall. While it is accepted that this case is not common, it provides a starting point for testing the IPS against cases of systematically increasing complexity. The length of the wall activated in the thermal response test of $3.5 \mathrm{~m}$ and the activation depth is $15 \mathrm{~m}$.

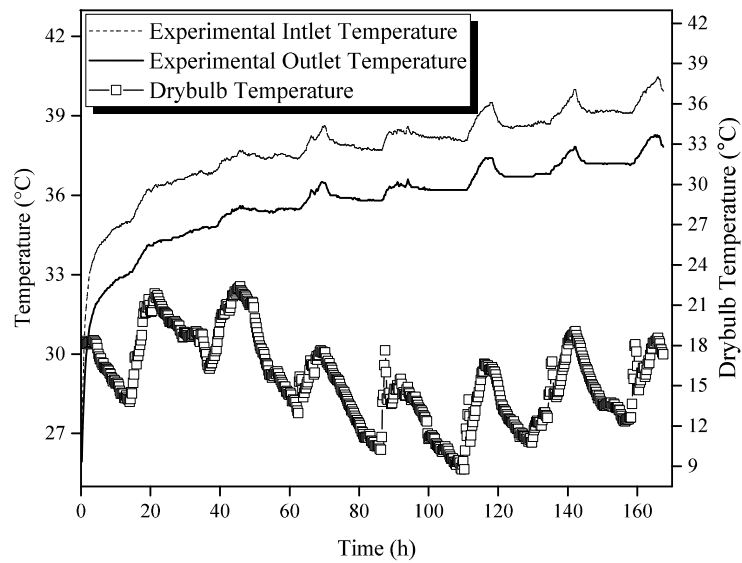

Fig. 1. Variations of inlet and outlet fluid temperatures in a DWHE surrounded by ground on both sides [18].

Figure 1 illustrates the trend for temperature increase over a course of 167.5 hours when water was used as the heat exchanger fluid. We employed the thermal data from the same DWHE in Equation (7) to investigate its performance in predicting the temperature evolution in a DWHE and the result is shown in Figure 2. Table 1 details the inputs to the IPS equation. While the total heat transfer to the wall was $20 \mathrm{~W} / \mathrm{m}^{2}$, we only employ half this value in the analysis to reflect the heat transfer process which happens in both directions from the wall, which at the time of the test, remained fully embedded on both sides. The value of $x$ used is $7 \mathrm{~cm}$ to represent the space between the embedded heat exchanger pipes and the wall surface that is in contact with the soil.

For comparison purposes, we used the OpenFOAM library [21] to compute conduction heat transfer in a twodimensional domain representing the semi-infinite ground with constant heat flux on the boundary representing the DWHE over the same time period.

The other side of the domain parallel to the surface representing the DWHE was kept at a constant temperature, similar to the initial ground temperature, while the other two boundaries were given adiabatic conditions. The results are displayed in Figure 3 and show very good agreement. This indicates that the IPS solution is a correct representation of the physical problem within the constraints of the assumed boundary conditions.

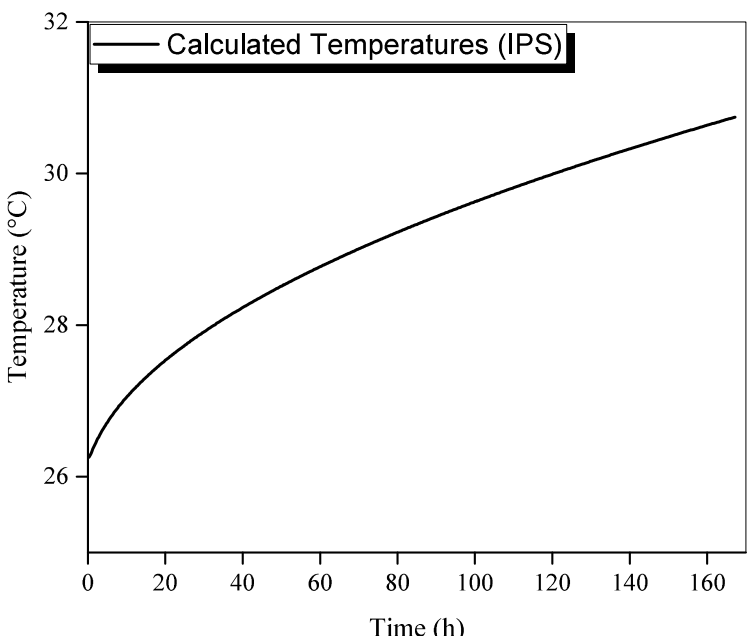

Fig. 2. Variations of wall surface temperature calculated using Equation (7).

Table 1. Inputs used in Equation (7) to plot Figure 2.

\begin{tabular}{|c|c|c|}
\hline Input Type & Value & Unit \\
\hline Heat Flux, $Q_{0}$ & 10 & $\mathrm{~W} / \mathrm{m}^{2}$ \\
\hline Thermal Conductivity, $\lambda$ & 1.5 & $\mathrm{~W} / \mathrm{m}^{\circ} \mathrm{C}$ \\
\hline Thermal Diffusivity, $\alpha$ & 0.7 & $\mathrm{~mm}^{2} / \mathrm{s}$ \\
\hline Distance from the Heated Wall, $x$ & 70 & $\mathrm{~mm}$ \\
\hline Initial Ground Temperature, $T_{0}$ & 26.25 & ${ }^{\circ} \mathrm{C}$ \\
\hline
\end{tabular}

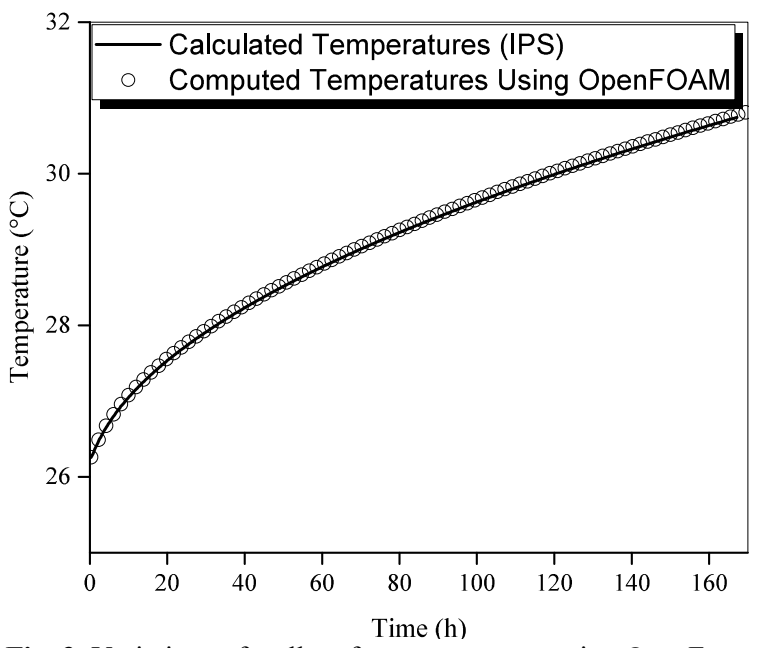

Fig. 3. Variations of wall surface temperature using OpenFoam library [21]. 


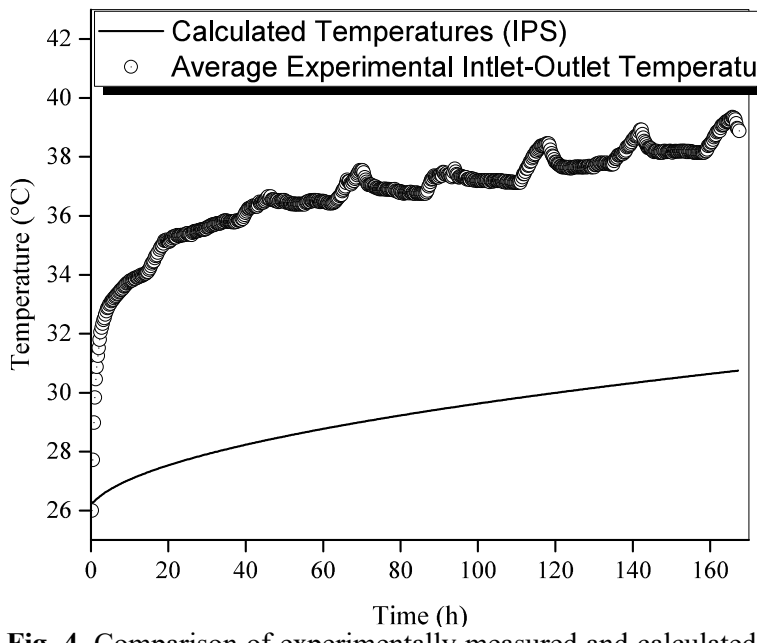

Fig. 4. Comparison of experimentally measured and calculated temperatures of the DWHE.

Figure 4 illustrates the comparison between the wall temperature calculated using Equation (7) and the average of the experimentally measured inlet and outlet fluid temperatures for the studied DWHE. It is to be expected that the IPS model gives a smaller temperature change than given by the field data. This is because the IPS calculates the temperature change at the back of the wall $(T)$. The average temperature change of the fluid circulating $\left(T_{f}\right)$ in the pipes would be expected to be the sum of this and the temperature change across the wall, which can be characterised by a thermal resistance term, $R$, (e.g. [22]):

$$
T_{f}=Q_{0} R+T
$$

Using this conceptual model it would be expected that the difference between $T$ calculated by the IPS (Equation (7)) and $T_{f}$ should increase with time as the heat capacity of the wall is overcome and the wall comes to a thermal steady state.

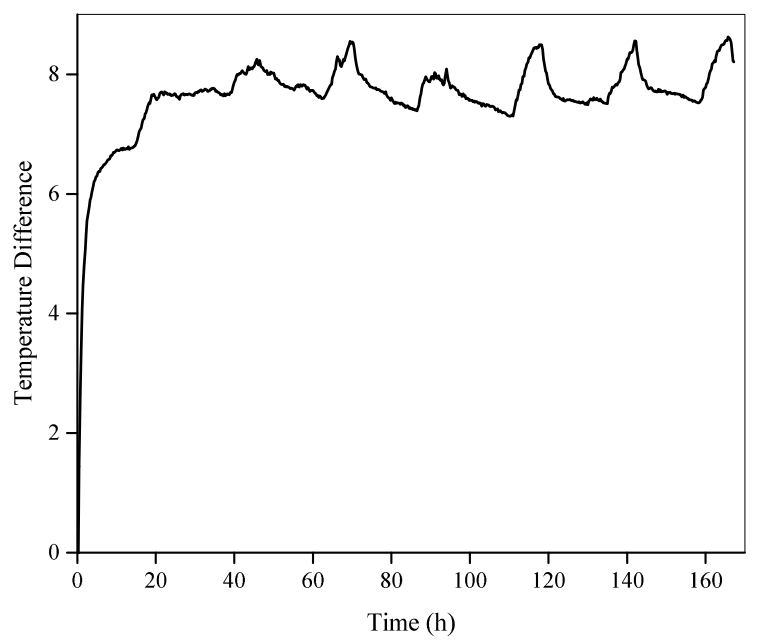

Fig. 5. The difference between the IPS derived temperature and the experimental mean fluid temperature from a thermal response test on a DWHE.
If we plot this temperature difference (Figure 5), we see that this is broadly the case, with the temperature difference approaching around 8 degrees. A constant value is not reached due to the peaks and troughs in the original field data representing the test interference with the ambient air conditions. This means that the applied heating power is not truly constant and hence a true steady state is not reached. The 8 degree temperature difference suggests that this half of the wall has resistance of around $0.8 \mathrm{~m}^{2} / \mathrm{kW}$, which is not unreasonable in the context of the results presented in [22] for thermal resistance of DWHE.

These results therefore demonstrate that the next step for development of analytical models for DWHEs is to couple Equation (7) with a steady state resistance model such as that of [22]. This will not offer a solution that works at very short time (e.g. the initial 20 hours in Figure 5 ), but would offer a complete approach for the long term. It will then also be important to consider the influence of both sides of the retaining wall, which will have different boundary conditions within the excavation. An additional task will be to test the size of thermally activated wall which is required for the assumptions of an infinite plane source to hold approximately correct under different timescales.

\section{Conclusions}

The infinite plane source (IPS) method was employed to assess the temperature change in the ground surrounding a diaphragm wall heat exchangers (DWHEs). The method was confirmed to be appropriate with reference to numerical studies of the same boundary conditions. When in comparison with field data it is clear that further development is needed to account for the temperature change within the retaining wall itself. Nonetheless there is precedence for this approach in the analysis of other GHE and the technique remains a promising one for speeding up analysis of the thermal performance of DWHEs.

This work was possible thanks to the research project "Integrated Infrastructure for Sustainable Thermal Energy Provision (IN-STEP)" funded by the UK's Engineering and Physical Sciences Research Council [EP/S001417/1].

\section{References}

1. D. Pahud, D. Dock, D. Terminal, E. Flughafens, V.Z. In, "Measured Thermal Performances of the Dock Midfield Energy Pile System at Zürich Airport", Proceedings of $9^{\text {th }}$ IEA Heat Pump Conference, 1 (2008)

2. P.J. Bourne-Webb, B. Amatya, K. Soga, T. Amis, C. Davidson, P. Payne, "Energy pile test at Lambeth College, London: Geotechnical and Thermodynamic Aspects of Pile Response to Heat Cycles", Géotechnique 59, 37 (2009)

3. D. Garber, "Ground Source Heat Pump System Models in an Integrated Building and Ground Energy Simulation Environment", PhD thesis (2013) 
4. F.A. Loveridge, W. Powrie, "The Average Temperature of Energy Piles", Geo-Chicago (2016)

5. K. Soga, Y. Rui, "Energy geostructures”, Advances in Ground-Source Heat Pump Systems; (2016)

6. H. Brandl, "Energy Foundations and other ThermoActive Ground Structures", Géotechnique 56, 81 (2006)

7. D. Adam, R. Markiewicz, "Energy from EarthCoupled Structures, Foundations, Tunnels and Sewers", Géotechnique 59, 229 (2009)

8. C. Xia, M. Sun, G. Zhang, S. Xiao, Y. Zou, “. Experimental Study on Geothermal Heat Exchangers Buried in Diaphragm Walls", Energy Build 52, 50 (2012)

9. M. Sun, C. Xia, G. Zhang, "Heat Transfer Model and Design Method for Geothermal Heat Exchange Tubes in Diaphragm Walls", Energy Build 61, 250 (2013)

10. S. Kürten, D. Mottaghy, M. Ziegler, “A New Model for the Description of the Heat Transfer for Plane Thermo-Active Geotechnical Systems Based on Thermal Resistances", Acta Geotechnica 10, 219 (2015)

11. P.J. Bourne-Webb, S. Burlon, S. Javed, S. Kürten, F.A. Loveridge, "Analysis and Design Methods for Energy Geostructures", Renew Sustain Energy Rev 65, 402 (2016)

12. P.J. Bourne-Webb, T.M. Bodas Freitas, R.A. Da Costa Gonçalves, "Thermal and Mechanical Aspects of the Response of Embedded Retaining Walls used as Shallow Geothermal Heat Exchangers", Energ Build 125, 130 (2016)

13. A. Coletto, D. Sterpi, "Structural and Geotechnical Effects of Thermal Loads in Energy Walls", Procedia Engineering 158, 224 (2016)

14. A. Di Donna, F. Cecinato, F.A. Loveridge, M. Barla, "Energy Performance of Diaphragm Walls Used as Heat Exchangers", Proceedings of the Institution of Civil Engineers - Geotechnical Engineering 170, 232 (2017)

15. D. Sterpi, G. Tomaselli, A. Angelotti, "Energy Performance of Ground Heat Exchangers Embedded in Diaphragm Walls: Field Observations and Optimization by Numerical Modeling", Renew Energy 147, 2748 (2020)

16. D. Rammal, H. Mroueh, S. Burlon, "Thermal Behaviour of Geothermal Diaphragm Walls: Evaluation of Exchanged Thermal Power", Renew Energy 147, 2643 (2020)

17. M. Barla, A. Di Donna, A. Santi, "Energy and Mechanical Aspects on the Thermal Activation of Diaphragm Walls for Heating and Cooling", Renew Energy 147, 2654 (2020)

18. I. Shafagh, S.J. Rees, I. Urra Mardaras, M. Curto Janó, M. Polo Carbayo, "A Model of a Diaphragm Wall Ground Heat Exchanger", Energies 13, 300 (2020)
19. F. Loveridge, McCartney J.S., Narsilio, G., Sanchez, M. "Energy Geostructures: A Review of Analysis Approaches, In Situ Testing and Model Scale Experiments.", Geomechanics for Energy and the Environment, 22, May (2020)

20. H.S. Carslaw, J.C. Jaeger, "Conduction of Heat in Solids", (1959)

21. H.G. Weller, G. Tabor, H. Jasak, C. Fureby, "A Tensorial Approach to Computational Continuum Mechanics Using Object-Oriented Techniques", Computers in Physics 12, 620 (1998)

22. I. Shafagh, S.J. Rees, "Analytical Investigations into Thermal Resistance of Diaphragm Wall Heat Exchangers", Proceedings of the European Geothermal Congress (2019) 